\title{
Common Mental Disorders and Its Socio-Demographic Correlates Among Women Of Reproductive Age In Urban And Rural Area Of Meerut
} Vertika Agarwal ${ }^{1}$, Seema Jain ${ }^{2}$, Sunil Kumar Garg ${ }^{3}$, Ganesh Singh ${ }^{4}$, Chhaya Mittal ${ }^{5}$

${ }^{1}$ Junior Resident, Department of Community Medicine, Lala Lajpat Rai Memorial Medical College, Meerut-250004, U.P; ${ }^{2}$ Professor, Department of Community Medicine, Lala Lajpat Rai Memorial Medical College, Meerut-250004, U.P; ${ }^{3}$ Professor and Head, Department of Community Medicine, Lala Lajpat Rai Memorial Medical College, Meerut-250004, U.P; ${ }^{4}$ Professor, Department of Community Medicine, Lala Lajpat Rai Memorial Medical College, Meerut-250004, U.P; ${ }^{5}$ Associate Professor, Department of Community Medicine, Lala Lajpat Rai Memorial Medical College, Meerut-250004, U.P

\begin{tabular}{|c|c|c|c|c|c|c|c|c|}
\hline Abstract & Introduction & Methodology & $\underline{\text { Results }}$ & Conclusion & $\underline{\text { References }}$ & Citation & \multicolumn{2}{|c|}{ Tables / Figures } \\
\hline \multicolumn{9}{|c|}{ Corresponding Author } \\
\hline \multicolumn{8}{|c|}{$\begin{array}{l}\text { Dr. Vertika Agarwal, Department of Community Medicine, Lala Lajpat Rai Memorial Medical College, } \\
\text { Meerut-250004, Uttar Pradesh } \\
\text { E Mail ID: drvertika.0620@gmail.com }\end{array}$} & 口ifin \\
\hline
\end{tabular}

\section{Citation}

Agarwal V, Jain S, Garg SK, Singh G, Mittal C. Common Mental Disorders and Its Socio-Demographic Correlates Among Women Of Reproductive Age In Urban And Rural Area Of Meerut. Indian J Comm Health. 2020;32(2):359-364.

Source of Funding: Nil Conflict of Interest: None declared

\section{Article Cycle}

Received: 19/03/2020; Revision: 08/04/2020; Accepted: 25/05/2020; Published: 30/06/2020

This work is licensed under a Creative Commons Attribution 4.0 International License.

\section{Abstract}

Background: Common Mental disorders are distress states manifesting with anxiety, depressive and unexplained somatic symptoms categorized as 'neurotic, stress-related and somatoform disorders' in ICD-10. These are 2-3 times more common in women than in men and also more in urban area than rural. Women of reproductive age are at higher risk especially those with social disadvantage, low income and low education. Aims \& Objectives: To assess the prevalence of common mental disorders and associated socio-demographic factors among women of reproductive age (15-49 years) residing in urban and rural area of Meerut. Material and Methods: This was a cross-sectional study done in urban and rural area of Meerut from June 2018 to October 2019. 267 women in reproductive age (15-49years) were interviewed in urban as well as rural area using a predesigned pretested questionnaire regarding socio-demographic profile. Self- Reporting Questionnaire-20 was used to determine presence of common mental disorders. Results: Overall prevalence of common mental disorders among women of reproductive age group was $19.8 \%(106)$ with $24.2 \%(65)$ in urban and $15.4 \%(41)$ in rural area. Statistical analysis revealed that various socio-demographic variables like belonging to urban area (24.2\%), being widowed/separated (urban-85.7\%;rural75.0\%), belonging to broken family(urban-54.5\%\%; rural-58.3\%), being employed(urban-39.6\%;rural-33.3\%) and lower socioeconomic status(urban-54.5\%;rural-40.0\%) were significantly associated with presence of common mental disorders. In urban women increasing age was also associated with common mental disorders. Conclusion: The study revealed a high prevalence of common mental disorders in both urban and rural area and a significant association with various sociodemographic variables.

\section{Keywords}

Common mental disorders; women of reproductive age; rural; urban

\section{Introduction}

Since ancient times in India, great importance has been given to the concept of healthy mind. Practices of "yoga" and "meditation", which emphasized on 'chittavrittinirodha' i.e. to calm the oscillation of the mind, is inherent to Indian culture. Yet in recent years there has been an alarming rise in the burden of mental disorders in India with almost 9 million people suffering from severe incapacitating mental disorders and almost 90 million suffering from mild mental illness.(1) National Mental Health Survey conducted in India in 2015-2016, reported an overall lifetime prevalence of mental illness as $13.7 \%$ with neurosis and stress related disorders affecting twice as many women than men and more in urban than rural areas.(2)

Common mental disorders (CMDs), a term coined by Goldberg and Huxley to describe mental disorders that are encountered commonly in primary and community health care settings includes distress states manifesting with 
anxiety, depressive and unexplained somatic symptoms.(3) They are the non-psychotic affective disorders, classified as separate diagnostic category in ICD-10 as 'neurotic, stress-related and somatoform disorders'.(4) CMDs have impact on the mood and feelings of affected persons(5) and are found to be strongly associated with functional disability.(6) Woman in the patriarchal society as India is highly vulnerable to poor mental health with a worse scenario among women in reproductive age.

\section{Aims \& Objectives}

To study the prevalence of common mental disorders and the associated socio-demographic factors among women in reproductive age (15-49 years) residing in urban and rural area of Meerut.

\section{Material \& Methods}

Study Type: Cross-sectional study.

Study Area: The urban and rural area of Meerut

Study population: In urban area study was conducted in population covered by Urban Health Training Centre, Surajkund and in rural area among population covered by Community Health Center, Machhra Block. These centers serve as urban and rural field practice area of Department of Community Medicine, L.L.R.M. Medical College, Meerut respectively.

Study duration: June 2018 to October 2019.

Sample size calculation: The sample size was estimated as 267 by taking prevalence of common mental disorders among reproductive age women (15-49years) in rural area as $10.7 \%$ (7) and in urban area as $22.1 \%$ (8) at $95 \%$ confidence interval and $95 \%$ power, using formula $n=$ $\left(z_{\dot{\alpha}}+z_{(1-\beta)}\right) 2(p 1 q 1+p 2 q 2) /(p 1-p 2) 2.9$ So , 267 women in age 15-49 years were included in urban as well as rural area . Inclusion criteria: All women aged $15-49$ years who gave consent.

Exclusion criteria: Women with psychotic illness, mental retardation, poor hearing, serious illness or those unavailable on day of visit or showed hostile behaviour.

Strategy for data collection: In the urban area there are 9 localities registered at UHTC. Before starting the survey a baseline information about number of women aged 15-49 years in each area was collected from urban health centre. Proportionate number of women were interviewed from among total women of reproductive age in each locality using probability proportional to size method. In the rural area multistage sampling was done. There were 5 functional PHCs under RHTC (CHC, Machhra) from which PHC Kayasth Badda was selected randomly. PHC Kayasth Badda has 5 functional subcenters and Subcenter Bhattipura was randomly selected. Subcentre Bhattipura serves two villages, namely Bhattipura and Meghrajpur. The survey was done in both these villages. The total population of women in these villages was obtained from CHC Machhra database. According to "Women and Men in India -A statistical compilation of Gender related
Indicators in India,2018 20th issue"10, women in rural Uttar Pradesh constitute $47.85 \%$ of the total population of which $57.8 \%$ are in age group $15-49$ years. Using this data the population of women aged 15-49 years to be surveyed in particular village was calculated using probability proportional to size method.

From each locality/village first house was selected randomly. The random house allocation was done by pencil/pen tip drop method to start the survey. Then house to house survey was done picking all the eligible women in the adjacent houses towards right of the first house till the required sample size for that locality/village were covered. If the house had more than one eligible women all were interviewed. During home visits each women was interviewed using oral questionnaire method after taking verbal informed consent. If any of the women in the family was absent or hostile during the time of study, she was excluded. Detailed information was collected on predesigned and pretested proforma about socio-demographic profile. Self-Reported Questionnaire20 (SRQ-20) a standardized and validated tool developed by WHO in 1994 was used to determine the presence of common mental disorders by personal interview method. Data obtained was tabulated and statistically analysed. Anonymity of participants was maintained throughout the study. All participants who screened positive for CMD were referred to psychiatrist. $(9,10)$

\section{Working definition :}

Common mental disorders: To ascertain presence of common mental disorder in study population Self Reporting Questionnaire -20 was used at cutoff score "10".

Self Reporting Questionnaire-20 (SRQ-20) : This is a 20 item questionnaire developed by World Health Organisation (11), requiring answers in yes/no format and screens for presence of common mental disorders. SRQ has been standardized in India in two studies Chincholikar (2004)(12) and Patel et al (2008)(13). Respondents were asked about experiencing any of 20 listed symptoms since last 4 weeks and a cut off score '10' was regarded as presence of Common Mental Disorders. $(12,13)$

Ethical approval: This study was approved by the Institute's ethical committee and verbal informed consent was taken from all the participants.

Consent: Each participant was interviewed after taking verbal informed consent.

Statistical analysis: Data collected was entered and analysed by Epi Info 7.0 software. Association between common mental disorders and various socio-demographic factors was assessed using Pearson's Chi square test. P value $<0.05$ was taken as statistically significant.

\section{Results}

In the present study a total of 536 women of reproductive age group participated, 267 in rural and 269 in urban area (last house had more than one eligible women). The 
overall prevalence of common mental disorders among women of reproductive age was $19.8 \%$ (106) with a statistically significant difference in urban and rural area being $24.2 \%$ and $15.4 \%$ respectively. The mean SRQ score among women with common mental disorder was almost same in urban and rural area being $12.2 \pm 1.9$ and $12.0 \pm$ 2.0 respectively.

As seen in (Table 1), in urban area an increasing trend was seen in common mental disorders with increase in age of women as $44.4 \%$ women in age $45-49 y$ rs had common mental disorders followed by $38.7 \%$ in those with age 40 $44 y$ rs and was least among 20-24years age being $7.1 \%$ $(\mathrm{P}<0.05)$. However, no significant association was found between age and presence of common mental disorders in rural area. Marital status was also significantly associated with common mental disorders. It was seen $85.7 \%$ of widowed/separated women in urban area were suffering from common mental disorders compared to $23.6 \%$ married and $13.8 \%$ unmarried women $(P<0.05)$. Similarly, in rural area $75.0 \%$ of widowed/ separated women were having common mental disorders while only $12.8 \%$ of married and $8.3 \%$ of unmarried women $(P<0.001)$. Type of family was also found significantly associated with presence of CMD. In rural area $58.3 \%$ women belonging to broken family were suffering from common mental disorders compared to $17.3 \%$ in nuclear and $9.9 \%$ in joint family whereas in urban area $54.5 \%$ women belonging to broken family were suffering from these disorders compared with $24.6 \%$ in nuclear and $20.7 \%$ in joint family. No significant association was found between caste and presence of common mental disorders.

Another factor that was found significant was occupation. It was seen that $33.3 \%$ of employed women in rural and $39.6 \%$ in urban area had common mental disorders as compared to $10.8 \%$ and $20.4 \%$ in unemployed women in urban and rural area respectively. Illiterate women were found to be suffering more from CMD in both rural (19.3\%) and urban (37.1\%) area and prevalence gradually decreased with increasing literacy level. However, this association with education status was not found to be statistically significant $(P>0.05)$. The prevalence of common mental disorders was also found to be associated with socioeconomic status in both rural and urban area as the prevalence was lowest among women belonging to upper class (12.2\% in urban and $6.5 \%$ in rural area) and was maximum among those belonging to lower class being $54.5 \%$ in urban and $40.0 \%$ in rural area respectively. (Table 2) A rising trend of common mental disorders on going from upper class to lower class in both rural and urban area was observed in the study . (Figure 1)

\section{Discussion}

The prevalence of common mental disorder in this study is quiet high in both rural and urban area, being $24.2 \%$ and $15.4 \%$ respectively. The prevalence in rural area is much higher than $10.7 \%$ reported by Shindaye and Patel (2010)(7) who used GHQ-12 for screening of CMD compared to SRQ-20 used in present study while in urban area is slightly higher than $22.1 \%$ found by Panigrahi et al (2017)(8) in Bhubaneswar probably because they included only married women while in present study all women in age 15-49 years irrespective of their marital status were included.

The prevalence of these disorders was significantly higher among urban women (24.2\%) than in rural women (15.4\%) which is consistent with findings of Indian studies done by National Mental Health Survey,2015-2016, India (2). This could be due to higher stress and conflict in urban women to keep pace with the faster growing modern life along with maintaining traditional Indian values. Also she has more responsibilities of both home and outside affairs compared to rural women where the outside affairs are dealt mostly by males.

The prevalence of common mental disorders significantly increases with increasing age in urban area which is similar to finding of Panigrahi et al (2017)(8) in Bhubaneshwar. The women in advanced age is predisposed to higher degree of stress compared to younger counterparts as she has to fulfill increased demand of family, especially that of young children who are in formative years of their life and require more care and support from their mother. But age had no significant association in rural area, similar to Shindaye and Patel (2010).(7)

Widowed/separated women in urban as well as rural area (75\% and $85.7 \%$ respectively) were suffering more with these disorders than those who were married or unmarried. These findings were consistent with that of Fahey et al (2016)(14) in rural area and Sathyanarayana et al (2019)(15) in urban area. The widowed/separated women has to bear the loss of life partner along with unshared responsibility of household, the social stigma and social exclusion that she has to face in a conservative Indian society which keeps her state of mental stress thus predisposing for depression, anxiety etc.

Women who were employed $(33.3 \%$ and $39.6 \%$ in rural and urban area respectively) had higher prevalence of CMD compared to those unemployed. Working women have dual responsibilities both of home and workplace which results in role conflicts and thus more stress predisposing them to poor mental health. Similar findings were reported by Panigrahi et al (2017)(8) in Bhubaneswar and Sathyanarayana et al (2019)(15) in Bangalore.

The study also revealed the impact of poor socioeconomic status on presence of common mental disorders. The study revealed that the prevalence of CMD increased from upper to lower socio-economic class both in rural and urban area. Women in lower socioeconomic status are in constant struggle to make their ends meet. Being financially deprived predispose them to increased stress and thus poor mental health. Similar findings were 

reported by Shindaye and Patel (2010) (7) in rural areas of India and Sathyanarayana et al (2019)(15) in urban area of Bangalore.

\section{Conclusion}

The present study from Uttar Pradesh shows high prevalence of common mental disorders in women of reproductive age group in rural (15.4\%) as well as urban area (24.2\%). The prevalence was higher in urban area. Socio-demographic factors having significant association with higher prevalence of common mental disorders were advancing age, being widowed, living in broken family, being employed and belonging to lower socio-economic status. The women in these situations are in need of more care and support so that they can lead a more productive and happy life.

\section{Recommendation}

1. Opportunistic Screening of women for mental illness must be encouraged. For this they can be targeted at places frequently visited by them like clinics, schools, offices, work places, places of worship.

2. Training of family physicians and gynecologist, who are first point of contact in case of any illness, for screening women for mental illness using easy and rapidly administered tools like SRQ-20 and referring them to a psychiatrist if needed.

3. Capacity building of paramedical staff and grass root level health workers like ASHA, ANM, LHW etc in rural areas, to identify 'at risk' women and refer them. Encouraging them to educate women and community about mental illnesses to eliminate stigma which acts as a barrier to obtain and deliver mental health services.

4. Modifying existing healthcare policies for women by adopting a holistic approach with equal focus on mental health and strengthening District Mental Health Programme to increase community awareness about common mental disorders, their treatment and prevention. NGOs should be engaged to conduct community outreach sessions and awareness camps on common mental disorders.

5. Researches must be undertaken in field community psychiatry and efforts must be made to fill the gap of psychiatrist by increasing seats in M.D psychiatry and clinical psychology.

\section{Limitation of the study}

The study has few limitations. Firstly, the study used SRQ20 at cut-off 10 to define the presence of common mental disorders so there might be a possibility of missing some probable cases who did not meet the cut off criteria. Also as the symptoms were self reported it could be a source of bias. However, to minimize the bias the participants were cross-questioned so as to ascertain the presence of reported symptoms. Also, there could be pseudo inflation in results as the study did not exclude women in certain stages of life known to precipitate stress such as pregnancy, separation from partner, death of spouse.

\section{Relevance of the study}

The study helps to understand the current burden of common mental disorders among the study population and their associated factors which can aid to identify the lacunae in service delivery. It will also help to plan and implement appropriate health strategies so as to reduce burden of these disorders which is on rising toll in current time.

\section{Authors Contribution}

The study was done under the guidance of Seema Jain (Professor) as main guide and S.K Garg (Professor \& Head), Ganesh Singh (Professor), Chhaya Mittal (Associate Professor) were co-guides. All the authors were involved in intellectual content, conception and design of study along with analysis and interpretation of data as well as writing of manuscript.

\section{References}

1. Global, regional, and national incidence, prevalence, and years lived with disability for 301 acute and chronic diseases and injuries in 188 countries, 1990-2013: a systematic analysis for the Global Burden of Disease Study 2013. Lancet. 2015 Aug 22;386(9995):743800. doi: 10.1016/S0140-6736(15)60692-4. Epub 2015 Jun 7. Review. PubMed PMID: 26063472; PubMed Central PMCID: PMC4561509.[PubMed].

2. Gururaj $G$ et al : National Mental Health Survey of India, 2015-16: Prevalence ,pattern and outcome. NIMHANS Publication, Bengaluru, 129,2016

3. Patel V, Pereira J, Coutinho L, Fernandes R. Is the labelling of common mental disorders as psychiatric illness clinically useful in primary care?. Indian J Psychiatry. 1997 Jul;39(3):239-46. PubMed PMID: 21584081; PubMed Central PMCID: PMC2967121.[PubMed]

4. Patel $V$ and Kleinman A. Poverty and common mental disorders in developing countries. WHO Bulletin ,2003.http://www.who.int/bulletin/volumes/81/8/ Patel080 3.pdf.

5. Depression and Other Common Mental Disorders: Global Health Estimates (2017).World Health Organization 2017, Geneva.

6. Shamasundar C, Murthy SK, Prakash OM, Prabhakar N, Krishna DK. Psychiatric morbidity in a general practice in an Indian city. Br Med J (Clin Res Ed). 1986 Jun 28;292(6537):1713-5. doi: 10.1136/bmj.292.6537.1713. PubMed PMID: 3089368; PubMed Central PMCID: PMC1340639.[PubMed].

7. Shidhaye R, Patel V. Association of socio-economic, gender and health factors with common mental disorders in women: a population-based study of 5703 married rural women in India. Int J Epidemiol. 2010 Dec;39(6):1510-21. doi: 10.1093/ije/dyq179. Epub 2010 Oct 29. PubMed PMID: 21037247; PubMed Central PMCID: PMC2992631. [PubMed]

8. Panigrahi A, Panigrahi M, Padhy AP, Das SC. Common mental disorder and its socio-demographic correlates among married women residing in slum areas of Bhubaneswar, India. Women Health. 2017 May-Jun;57(5):521-533. doi: 10.1080/03630242.2016.1181137. Epub 2016 Apr 22. PubMed PMID: 27105141.[PubMed]

9. Ismail IM, Kulkarni AG, Meundi AD, Amruth M. A community based comparative study of prevalence and risk factors of hypertention among urban and rural populations in a coastal town of South India. Sifa Medical Journal 2016; 3:41-7

10. Women and Men in India (A statistical compilation of Gender related Indicators in India)-2018,20th issue, Ministry of statistics and programme implementation.2018. accessed through 
INDIAN JOURNAL OF COMMUNITY HEALTH / VOL 32 / ISSUE NO 02 / APR - JUN 2020 http://www.mospi.gov.in/sites/ default /files/publication_reports/Women\%20and\%20Men\%20\%20in\%20 India\%20 2018.pdf

11. Beusenberg, M, Orley, John $\mathrm{H}$ \& World Health Organization. Division of Mental Health. (1994). A User's guide to the self reporting questionnaire (SRQ / compiled by M. Beusenberg and J.Orley. World Health Organization. https://apps.who.int/iris/handle/10665/61113

12. Chincholikar S.V. Use of SRQ in Psychiatric epidemiology. Indian Journal of Community Medicine,2004;29(4),190-911

13. Patel V, Araya R, Chowdhary N, King M, Kirkwood B, Nayak S, Simon $\mathrm{G}$, Weiss HA. Detecting common mental disorders in primary care in India: a comparison of five screening questionnaires. Psychol
[Common Mental Disorders...] | Agarwal V et al Med. 2008 Feb;38(2):221-8. doi: 10.1017/\$0033291707002334. Epub 2007 Nov 30. PubMed PMID: 18047768; PubMed Central PMCID: PMC4959557.[PubMed].

14. Fahey N, Soni A, Allison J, Vankar J, Prabhakaran A, Moore Simas TA, Byatt N, Phatak A, O'Keefe E, Nimbalkar S. Education Mitigates the Relationship of Stress and Mental Disorders Among Rural Indian Women. Ann Glob Health. 2016 Sep - Oct;82(5):779-787. doi: 10.1016/j.aogh.2016.04.001. PubMed PMID: 28283129; PubMed Central PMCID: PMC5485235.[PubMed]

15. Sathyanarayana RK and Manjunatha S. Common mental disorders among women of reproductive age group in an urban area in Bengaluru. International Journal of Community Medicine and Public Health , 2019;6(4) 1768-1773

\section{Tables}

TABLE 1 COMMON MENTAL DISORDERS IN ASSOCIATION WITH AGE, MARITAL STATUS, TYPE OF FAMILY AND CASTE

\begin{tabular}{|c|c|c|c|c|c|c|c|c|}
\hline \multirow[t]{4}{*}{ Variable } & \multicolumn{4}{|c|}{ Rural } & \multicolumn{4}{|c|}{ Urban } \\
\hline & \multirow{2}{*}{\multicolumn{2}{|c|}{$\begin{array}{l}\text { Study population } \\
\qquad N=267\end{array}$}} & \multicolumn{2}{|c|}{ CMD } & \multicolumn{2}{|c|}{ Study population } & \multicolumn{2}{|c|}{ CMD } \\
\hline & & & \multicolumn{2}{|c|}{$\mathrm{N}=41$} & \multicolumn{2}{|c|}{$N=269$} & \multicolumn{2}{|c|}{$N=65$} \\
\hline & No. & $\%$ & No. & $\%$ & No. & $\%$ & No. & $\%$ \\
\hline \multicolumn{9}{|l|}{ Age } \\
\hline 15-19years & 19 & 7.1 & 1 & 5.3 & 17 & 6.3 & 3 & 17.6 \\
\hline 20-24years & 52 & 19.5 & 5 & 9.6 & 42 & 15.7 & 3 & 7.1 \\
\hline 25-29years & 71 & 26.6 & 11 & 15.5 & 53 & 19.7 & 13 & 20.8 \\
\hline 30-34years & 43 & 16.1 & 7 & 16.3 & 43 & 16 & 8 & 18.6 \\
\hline 35-39years & 22 & 8.3 & 4 & 18.2 & 56 & 20.8 & 14 & 25 \\
\hline 40-44years & 34 & 12.7 & 10 & 29.4 & 31 & 11.5 & 12 & 38.7 \\
\hline \multirow[t]{2}{*}{ 45-49years } & 26 & 9.7 & 3 & 11.5 & 27 & 10 & 12 & 44.4 \\
\hline & \multicolumn{4}{|c|}{$\chi 2: 8.43$, df: $6, P=0.208$} & \multicolumn{4}{|c|}{$\chi 2: 15.09$, df: $6, P=0.007$} \\
\hline \multicolumn{9}{|l|}{ Marital Status } \\
\hline Unmarried & 12 & 4.5 & 1 & 8.3 & 29 & 10.8 & 4 & 13.8 \\
\hline Married & 243 & 91 & 31 & 12.7 & 233 & 86.6 & 55 & 23.6 \\
\hline \multirow[t]{2}{*}{ Seperated/ Widow } & 12 & 4.5 & 9 & 75 & 7 & 2.6 & 6 & 85.7 \\
\hline & \multicolumn{4}{|c|}{$\chi^{2}: 34.56, \mathrm{df}: 2, \mathrm{P}=0.0001$} & \multicolumn{4}{|c|}{$\chi 2: 16.2$, df: $2, P=0.0003$} \\
\hline \multicolumn{9}{|l|}{ Type of family } \\
\hline Nuclear & 115 & 43.1 & 20 & 17.3 & 142 & 52.8 & 35 & 24.6 \\
\hline Joint & 140 & 52.4 & 14 & 9.9 & 116 & 43.1 & 24 & 20.7 \\
\hline \multirow[t]{2}{*}{ Broken family } & 12 & 4.5 & 7 & 58.3 & 11 & 4.1 & 6 & 54.5 \\
\hline & \multicolumn{4}{|c|}{$\chi 2: 20.51$, df: $2, P=0.00003$} & \multicolumn{4}{|c|}{$\chi 2: 6.32, \mathrm{df:} 2, \mathrm{P}=0.042$} \\
\hline \multicolumn{9}{|l|}{ Caste } \\
\hline General & 23 & 8.6 & 6 & 26.1 & 86 & 32 & 17 & 19.8 \\
\hline $\mathrm{OBC}$ & 130 & 48.7 & 15 & 11.5 & 88 & 32.7 & 22 & 25 \\
\hline \multirow[t]{2}{*}{$\mathrm{SC} / \mathrm{ST}$} & 114 & 42.7 & 20 & 17.5 & 95 & 35.3 & 26 & 27.4 \\
\hline & \multicolumn{4}{|c|}{$\chi 2: 3.91$, df: $2, P=0.141$} & \multicolumn{4}{|c|}{$\chi 2: 1.47, \mathrm{df}: 2, P=0.478$} \\
\hline
\end{tabular}

TABLE 2 ASSOCIATION BETWEEN COMMON MENTAL DISORDERS AND CASTE, EDUCATION, OCCUPATION AND SOCIO- ECONOMIC STATUS

\begin{tabular}{|c|c|c|c|c|c|c|c|c|}
\hline \multirow{4}{*}{$\begin{array}{c}\text { Socio-demographic } \\
\text { factors }\end{array}$} & \multicolumn{4}{|c|}{ Rural } & \multicolumn{4}{|c|}{ Urban } \\
\hline & \multirow{2}{*}{\multicolumn{2}{|c|}{$\begin{array}{l}\text { Study population } \\
\qquad N=267\end{array}$}} & \multirow{2}{*}{\multicolumn{2}{|c|}{$\begin{array}{l}\mathrm{CMD} \\
\mathrm{N}=41\end{array}$}} & \multicolumn{2}{|c|}{ Study population } & \multicolumn{2}{|c|}{ CMD } \\
\hline & & & & & \multicolumn{2}{|c|}{$N=269$} & \multicolumn{2}{|c|}{$N=65$} \\
\hline & No. & $\%$ & No. & $\%$ & No. & $\%$ & No. & $\%$ \\
\hline \multicolumn{9}{|l|}{ Education } \\
\hline Illiterate & 83 & 31 & 16 & 19.3 & 35 & 13 & 13 & 37.1 \\
\hline Primary & 43 & 16.1 & 8 & 18.6 & 25 & 9.3 & 9 & 36.0 \\
\hline Middle school & 51 & 19.1 & 8 & 15.7 & 51 & 18.9 & 14 & 27.5 \\
\hline High school & 36 & 13.5 & 5 & 13.9 & 36 & 13.4 & 10 & 27.8 \\
\hline
\end{tabular}




\begin{tabular}{|c|c|c|c|c|c|c|c|c|}
\hline \multicolumn{9}{|c|}{ INDIAN JOURNAL OF COMMUNITY HEALTH / VOL 32 / ISSUE NO 02 / APR - JUN 2020} \\
\hline Intermediate & 32 & 12 & 2 & 6.3 & 49 & 18.2 & 9 & 18.4 \\
\hline \multirow[t]{2}{*}{$\begin{array}{c}\text { Graduate and } \\
\text { above }\end{array}$} & 22 & 8.3 & 2 & 9.1 & 73 & 27.2 & 10 & 13.7 \\
\hline & \multicolumn{4}{|c|}{$\chi 2: 4.10, d f: 5, P=0.535$} & \multicolumn{4}{|c|}{$\chi 2: 10.95, d f: 7, P=0.052$} \\
\hline \multicolumn{9}{|l|}{ Occupation } \\
\hline Unemployed & 213 & 79.8 & 23 & 10.8 & 216 & 80.3 & 44 & 20.4 \\
\hline \multirow[t]{2}{*}{ Employed } & 54 & 20.2 & 18 & 33.3 & 53 & 19.7 & 21 & 39.6 \\
\hline & \multicolumn{4}{|c|}{$\chi 2$ :16.83, df: $1, P=0.00001$} & \multicolumn{4}{|c|}{$\chi 2: 8.60, d f: 1, P=0.003$} \\
\hline \multicolumn{9}{|c|}{ Socio-economic status } \\
\hline Upper & 31 & 11.6 & 2 & 6.5 & 41 & 15.2 & 5 & 12.2 \\
\hline Upper middle & 73 & 27.4 & 10 & 13.7 & 67 & 24.9 & 15 & 22.4 \\
\hline Middle & 77 & 28.8 & 10 & 13 & 83 & 30.9 & 19 & 22.9 \\
\hline Lower middle & 66 & 24.7 & 11 & 16.7 & 67 & 24.9 & 20 & 29.8 \\
\hline \multirow[t]{2}{*}{ Lower } & 20 & 7.5 & 8 & 40 & 11 & 4.1 & 6 & 54.5 \\
\hline & \multicolumn{4}{|c|}{$\chi 2: 11.81$, df: 4, $P=0.018$} & \multicolumn{4}{|c|}{$\chi 2: 10.12, d f: 4, P=0.038$} \\
\hline
\end{tabular}

\section{Figures}

FIGURE 1 COMMON MENTAL DISORDERS IN ASSOCIATION WITH SOCIO-ECONOMIC STATUS

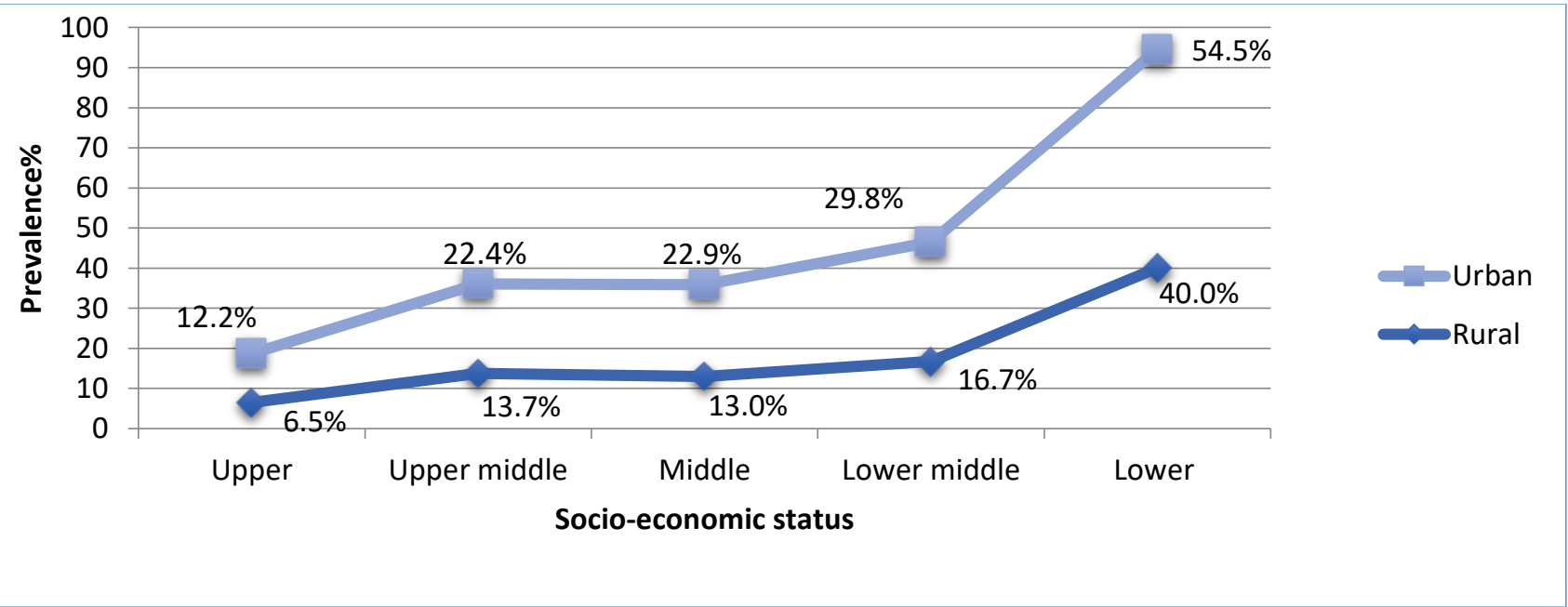

